\title{
Metodologia Ativa: Sala de Aula Invertida e suas Práticas na Educação Básica
}

\section{Active Methodology: Flipped Classroom and its Practices in Basic Education}

\author{
Zeni Terezinha Gonçalves Pereira * \\ Denise Quaresma da Silva \\ Universidade La Salle, Brasil
}

\begin{abstract}
Este estudo propõe uma investigação sobre a metodologia ativa chamada "sala de aula invertida" e suas práticas na educação básica, problematizando como estas ocorrem. Na introdução, justificamos a importância da temática como foco investigativo. Metodologicamente, trata-se de um estudo qualitativo, utilizou-se de uma revisão bibliográfica em dissertações produzidas em âmbito nacional que contemplaram os temas metodologia ativa, sala de aula invertida, sendo que a busca dos dados foi realizada no período de 2014 a 2018, na base de dados da CAPES de teses e dissertações a partir dos descritores "metodologia ativa" e "sala de aula inversa." Os resultados preliminares apontaram 36 dissertações, desse total 8 atenderam aos critérios de inclusão sendo 06 de mestrado scrito sensu e 02 de mestrado profissional, as demais foram excluídas por não estabelecer um diálogo adequado e em consonância com a temática. As conclusões apontaram que ao se pensar na sala de aula invertida como uma prática devemos considerar o papel fundamental da tecnologia, bem como a mudança de papel do professor que se torna o mediador do processo e entendemos que a sala de aula invertida se enquadra como uma estratégia de ensino-aprendizagem. Todavia, a educação básica demanda novos formatos de interação discente-docente-discente e ao que tudo indica as metodologias ativas estão conquistando espaço, mas ainda requerem apropriação por parte dos professores e demais envolvidos nos processos acadêmicos.
\end{abstract}

Palavras-chave: Educação básica; Teses; Salas de aula; Ensino; Métodos de ensino.

This study proposes an investigation about the active methodology called "inverted classroom" and its practices in basic education, problematizing how they occur. In the introduction, we justify the importance of the topic as an investigative focus. Methodologically, it is a qualitative study, it was used a bibliographical review in dissertations produced in a national scope that included the active methodology methodology, inverted classroom, and the search of the data was carried out in the period from 2014 to 2018 , in the database of the thesis and dissertations captions from the descriptors "active methodology" and "inverse classroom." Preliminary results indicated 36 dissertations, of which 8 met the inclusion criteria, being 6 masters scrito sensu and 02 professional masters, the others were excluded because they did not establish an adequate dialogue and in line with the theme. The conclusions pointed out that when thinking of the inverted classroom as a practice we must consider the fundamental role of technology as well as the changing role of the teacher who becomes the mediator of the process and we understand that the inverted classroom fits like a teaching-learning strategy. However, basic education demands new formats of student-teacher-student interaction, and it seems that active methodologies are gaining space, but still require appropriation by teachers and others involved in academic processes.

Keywords: Basic education; Theses; Classrooms; Teaching; Teaching methods.

*Contacto: ztgpereira@gmail.com

ISSN: $1696-4713$

www.rinace.net/reice/

revistas.uam.es/reice
Recibido: $\quad 1$ de marzo 2018

$1^{\text {a }}$ Evaluación: 23 de mayo 2018

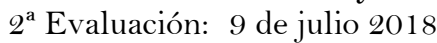

Aceptado: 27 de agosto 2018 


\title{
Introdução
}

Para se falar em tema emergente na área da educação, há que se considerar que um amplamente discutido e até mesmo praticado é o ensino híbrido que, conforme Horn e Stake (2015), tal ensino originou-se do ensino online, quando o termo ainda não era reconhecido, os autores ainda referem que "quando surgiu, o ensino online, de modo previsível, tinha reputação de ser uma alternativa secundária e barata para a sala de aula presencial tradicional" (p. 32).

Com o advento das tecnologias e das novas gerações adentrando em salas de aula, o/a professor/a tem sido demandado para utilização de metodologias de aulas mais atrativas, a fim de concretizar a relação ensino-aprendizagem. Muito se tem falado em metodologias ativas de aprendizado, contemplando dentre outros a chamada sala de aula invertida, foco desse estudo. Para Martins da Silva, Sampaio Lima y Bandeira Andriola (2016, p. 90), "os futuros professores devem ser preparados para enfrentar os desafios atuais de uma sociedade em constante mudança. Para tanto, torna-se essencial que aconteçam mudanças significativas na elaboração e execução de cursos que abordem especificamente a formação de professores".

Diante desse cenário de mudanças, surge a ideia de que o/a aluno/a possa atuar como protagonista de seu conhecimento e, que o/a professor/a seja um/a mediador/a desse processo, uma das formas é através de problematizações como estratégia emergente de ensino-aprendizagem.

\begin{abstract}
Quanto mais se problematizam os educandos, como seres no mundo e com o mundo, tanto mais se sentirão desafiados. Tão mais desafiados, quanto mais obrigados a responder ao desafio. Desafiados, compreendem o desafio na própria ação de captálo. Mas, precisamente porque captam o desafio como um problema em suas conexões com outros, num plano de totalidade e não como algo petrificado, a compreensão resultante tende a tornar-se crescentemente crítica, por isto, cada vez mais desalienada. (Freire, 1987, p. 40)
\end{abstract}

Freire (1987) assinala a possibilidade de se problematizar a educação, em detrimento da "bancária", ou seja, este autor de alguma maneira percebia a importância da utilização de algum viés do uso de metodologias ativas. Dentre as metodologias ativas atuais, fala-se em ensino aprendizagem baseado em problemas com proposições de leituras prévias e discussões de artigos de revistas, jornais e livros., ou seja, uma educação que não seja bancária, de acordo com os pressupostos freirianos.

\section{Fundamentação teórica}

Em seguida, ele é mostrado contemplados conceitos de metodologia ativa, modelos híbridos e suas características, estrutura e perfil da educação básica. Para tanto foram utilizados autores como Bergmann e Sams (2018) abordando sala de aula invertida, Horn e Staker (2015), Moran (2013) com suas abordagens sobre ensino híbrido e seus respectivos modelos de aprendizagem, Anastasiou e Alves (2007) com seu olhar sobre as estratégias de ensino aprendizagem, Freire (1987) com ideias acerca da autonomia do educando, dentre outros autores que embasaram esse estudo sob aspectos diversos. 


\title{
1.1. Metodologias ativas - modelos híbridos
}

Cada vez mais os profissionais da educação são demandados a dar aulas mais atrativas, mais dinâmicas e contemporâneas, diante disso, se deparam com as chamadas metodologias ativas de aprendizagem, que segundo Moran (2013) ocorrem através da apresentação durante o curso e/ ou disciplina (de forma antecipada) ao aluno de problemas e situações reais, que esses vivenciarão em suas realidades profissionais.

Ainda para Moran y Bacich (2018), o hibridismo sempre esteve presente no contexto educacional, pois nos espaços escolares sempre se misturou vários espaços, tempos, atividades, metodologias, públicos, técnicas. O que ocorre é que hoje tais ações estão em visibilidade, em virtude da "mobilidade e conectividade".

\begin{abstract}
O ensino é híbrido porque somos todos aprendizes e mestres, consumidores e produtores de informação e de conhecimento. Passamos, em pouco tempo, de consumidores da grande mídia a "prosumidores" -produtores e consumidores-de múltiplas mídias, plataformas e formatos para acessar informações, publicar, publicar nossas histórias, sentimentos, reflexões e visão de mundo. Somos o que escrevemos, o que postamos, o que "curtimos". Nisso expressamos nossa caminhada, nossos valores, visão de mundo, sonhos e limitações. (Moran, 2013, p. 28)
\end{abstract}

Existem, pelo menos, quatro formas de aplicação do ensino híbrido na educação básica e superior através de modelos distintos (figura 1), os quais poderão ser mesclados entre si.

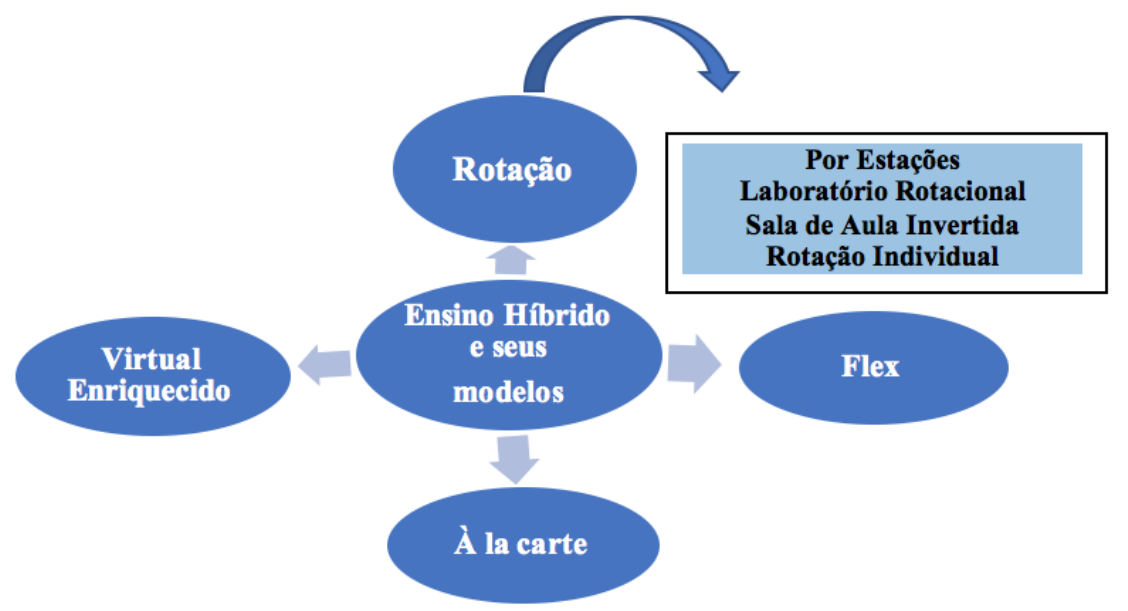

Figura 1. Modelos híbridos de aprendizagem

Fonte: Elaborado pelos autores.

Na figura 1 observamos que o modelo denominado rotação possui alguns desdobramentos, como a rotação por estações, a qual sua aplicabilidade poderá ser dentro de uma sala de aula ou várias salas de aula. Já o desdobramento tido como laboratório rotacional, guarda algumas semelhanças com o modelo anterior, porém consiste em encaminhar os alunos para o laboratório de informática para a parte de ensino online do curso, liberando dessa forma o tempo dos/as professores/as e o espaço da sala de aula, já que esses utilizarão um laboratório de informática (Horn e Staker, 2015). O desdobramento denominado "sala de aula invertida" (foco desse estudo) também apresenta algumas proposições das quais discutiremos mais adiante num capítulo à parte e, por fim no desdobramento do modelo "rotação" consta a chamada rotação individual que se diferencia dos demais modelos 
rotacionais, em virtude de que os/as alunos/as possuem cronogramas diários customizados de acordo com suas reais necessidades. Ainda sobre modelos híbridos e conforme observado na figura 1, existem outros modelos, porém esses não apresentam desdobramentos, por exemplo o modelo flex que segundo Horn e Staker (2015),

\begin{abstract}
O termo refere-se a cursos ou matérias em que ensino online é a espinha dorsal da aprendizagem do aluno, mesmo que às vezes direcione os estudantes para atividades presenciais. O professor tutore está no local, e os estudantes aprendem principalmente em uma escola tradicional, física, exceto por alguma lição de casa. Os estudantes movem-se pelo curso Flex de acordo com suas necessidades individuais. Professores estão disponíveis, presencialmente, para oferecer ajuda e, em muitos programas, iniciam projetos e discussões para enriquecer e aprofundar a aprendizagem, embora, em outros, eles estejam menos envolvidos. (p. 47)
\end{abstract}

Já o modelo à la carte, de acordo com os autores é comumente utilizado como ensino híbrido no ensino médio, diante de situações em que o/a aluno/a frequenta algum curso online concomitantemente com disciplinas regulares cursadas no ensino médio. Horn e Staker (2015, p. 49) ainda complementam que esse modelo "podem ter componentes presenciais, exatamente como ocorre nos cursos Flex", mas se diferenciam nos papeis desempenhados pelos docentes tendo em vista que no "modelo à la carte, $\mathrm{o} / \mathrm{a}$ professor/a tutor/a é o/a professor/a online, enquanto que no Flex, o/a professor/a tutor/a é o/a professor/a presencial".

O modelo chamado virtual enriquecido diz respeito aos cursos que oferecem encontros presenciais semanais obrigatórios e, permite ao aluno/a que complementem a aprendizagem no virtual / online de forma independente e de onde preferirem. Cabe ressaltar que não existe uma hierarquia entre os modelos mencionados na figura $1 \mathrm{e}, \mathrm{sim}$ possibilidades de aplicabilidade, inclusive de forma combinada, ou seja, adoção de mais de um modelo nas aulas.

Segundo Anastasiou e Alves (2007, p. 18), “[ ...] na realidade da sala de aula, pode ocorrer a compreensão, ou não, do conteúdo pretendido, a adesão, ou não, a formas de pensamento mais evoluídas, a mobilização, ou não, para outras ações de estudo e de aprendizagem”. A autora revelou, também, que é possível o avanço nas integrações disciplinares, através de um planejamento conjunto semestral ou anual, mesmo que o modelo curricular atenda aos moldes tradicionais. Toda prática educativa deve ter um propósito, planejada e sistematizada, independentemente da execução de novos modelos e/ou estratégias inovadoras (Camargo e Daros, 2018).

Com frequência os professores iniciantes e o desenvolvimento profissional oferecido
aos professores mais experientes priorizam o ensino e não a aprendizagem. A atenção
precisa se deslocar de como ensinar para como aprender, e apenas depois que os
professores forem capazes de compreender como os alunos aprendem é que eles podem
tomar decisões a respeito de como ensinar. (Hattie, 2017, p. 91)

$\mathrm{O}$ autor complementa que é preciso adotar uma aprendizagem convidativa, permeada por compromissos transparentes e, que dessa forma haverá diálogo entre professores/as e alunos/as quanto à compreensão dos conceitos presentes na aula. Corroborando com esse entendimento (Mora Reyes e Morales Rivera, 2016, p. 120) referem que “[...] não devemos limitar nossos processos de ensino a um único modelo, por causa da atratividade à primeira vista, porque não existe um modelo capaz de lidar com todos os tipos e estilos de aprendizagem". 
De todo modo, o que estes autores postulam é uma preocupação com a aprendizagem do/a aluno/a, embora não neguem a atenção necessária aos aspectos do ensino.

\title{
1.2. Sala de aula invertida
}

Nessa assertiva, a sala de aula invertida é apenas uma das formas do/a professor/a adotar a metodologia ativa. Embora seja um método que tem atraído cada vez mais adeptos, tratase de uma prática que requer, por parte do/a professor/a e dos/as alunos/as, uma outra dinâmica nos estudos. A sala de aula invertida (flipped classroom) é um modelo pedagógico criado em 2007 pelos professores de química norte-americanos, Jonathan Bergmann e Aaron Sams, os quais são considerados os pioneiros do modelo no ensino médio (Horn e Staker, 2015). Segundo Moran (2013):

\begin{abstract}
As instituições educacionais atentas às mudanças escolhem, fundamentalmente, dois caminhos: um mais suave-alterações progressivas-e outro mais amplo, com mudanças profundas. No caminho mais suave, elas mantêm o modelo curricular predominantemente disciplinar, mas priorizam o envolvimento maior do aluno, com metodologias ativas, como o ensino por projetos de forma mais interdisciplinar, o ensino híbrido ou blended e sala de aula invertida. (p. 29)
\end{abstract}

Para Bergmann e Sams (2018, p. 6) "a inversão da sala de aula estabelece um referencial que oferece aos estudantes uma educação personalizada, ajustada sob medida às suas necessidades individuais". Os autores complementam, ainda, que quando se fala em sala de aula invertida há que se considerar que quando o/a professor /a opta por essa metodologia, cabe a ele/a a prática do "fazer acontecer", pois a ideia central de tais práticas consiste em deslocar a atenção do/a professor/a para o aprendiz e seu respectivo aprendizado. Esse entendimento é corroborado por Bergamann e Sams (2018, p. 14) quando sinalizam que "a aula gira em torno dos alunos, não do professor, esse está presente unicamente para prover feedback especializado".

Nos Estados Unidos existe uma organização chamada Flipped Learning Network, que difunde conteúdos sobre aprendizagem invertida, a qual define como sendo uma abordagem pedagógica que atua na perspectiva que vai da aprendizagem individual para aprendizagem grupal, nesse caso com a presença do/a docente, ainda referem distinção entre a aprendizagem invertida (flipped learning) e a sala de aula invertida (flipped classroom), entendendo que essa última não necessariamente atingirá os propósitos de aprendizagem. Para esse propósito o docente terá que adotar novas formas, inclusive a de envolvimento e engajamento na aprendizagem invertida. Por essa razão, os membros da FLN $^{1}$ orientam que os docentes apropriem-se e pratiquem o chamado quatro pilares, traduzidos pela sigla FLIP, que consiste em: ambiente flexível (flexible environment), ou seja, fornecer espaços flexíveis de aprendizagem, aluno protagonizando onde e como aprender; cultura da aprendizagem (learning culture) transferindo o foco do/a professor/a para o/a aluno/a nos processos de aprendizagem, alunos ativamente envolvidos na construção do conhecimento; conteúdo intencional (intentional content) cabendo ao professor/a definir quais conteúdos necessitam ensinar e quais materiais compete ao aluno acessar por conta

${ }^{1}$ The Flipped Learning Network is a 501 (c) 3 with the mission of providing educators with the knowledge, skills, and resources to implement Flipped Learning successfully. The Four Pillars of F-L-I-PTM and the definition were written by the FLN's board members: Aaron Sams, Jon Bergmann, Kristin Daniels, Brian Bennett, Helaine W. Marshall, and Kari M. Arfstrom with additional support from experienced Flipped Educators. Recuperado de http://www.flippedlearning.org/domain/46 
própria; educador profissional, requerendo desse profissional uma postura diferente do/a professor/a do ambiente tradicional de aprendizagem, pois são mais demandados, conectados, tolerantes e aceitam críticas (Flipped Learning Network, 2014)

Nesse sentido, observa-se que os métodos tradicionais, em especial na educação básica ocorrem através da explanação dos conteúdos, precedida dos temas de casa, enquanto que na sala de aula invertida esse processo inverte-se no sentido de que o/a aluno/a se apropria do conteúdo em casa e nos momentos de sala de aula realiza trabalhos pertinentes ao preparo feito em casa, cabendo ao professor /a fazer retomadas pontuais das dúvidas dos/as alunos/as.

Para Horn e Staker (2015, p. 42), esse modelo é o "único que recebeu maior atenção na mídia até agora e que é assim denominada porque inverte completamente a função normal da sala de aula". Os autores complementam que o tempo do/a professor/a utilizado em sala de aula, passa a ser mais de cunho assistencial, no formato de mediação daquilo que o/a aluno/a já se apropriou do conhecimento em casa ou em outro lugar, via estudos online. Recomenda-se que esse/a professor/a se utilize desse tempo para práticas de projetos, resoluções de problemas ou até mesmo promover discussões acerca do conteúdo com os/as alunos/as, transformando esse tempo destinado à aprendizagem ativa. De acordo com Bergamnn e Sams (2018) nesse modelo o tempo precisa ser reestruturado em todos os momentos de aprendizagem.

Moran (2013) acrescenta que em virtude do dinamismo e das várias formas de comunicação deve haver um equilíbrio entre compartilhar e personalizar, pois segundo o autor é preciso encontrar tempo para "aprofundar, reelaborar, produzir e fazer novas sínteses", permitindo interações sociais de ideias e pessoas. Para alguns autores (Castro, 2012; Martins da Silva, Sampaio Lima e Bandeira Andriola, 2016) a busca da inovação como ferramenta para o desenvolvimento e melhorias das instituições de ensino superior requer a adoção de práticas de ensino tidas como inovadoras, justificando-se a ideia de dinamismo nas salas de aulas, no que tange à abordagem dos conteúdos.

\subsection{Educação básica}

De acordo com publicação do Senado Federal, a primeira Lei de Diretrizes e Bases da Educação (LDB), Lei $\mathrm{N}^{\circ}$ 4.024 foi promulgada em 1961, instituindo disciplinas comuns a todos os cursos, e a partir desta, foram apresentadas outras versões, sendo que na segunda versão dez anos após, vislumbra-se um sistema de ensino semelhante às práticas atuais. Nessa época crescia a participação das mulheres no ensino público, a conclusão do ensino primário estava condicionada a oito anos e utilizava-se os termos $1^{\circ}$ e $2^{\circ}$ grau, como segunda fase da vida escolar, com enfoques mais técnico em virtude do regime militar que prevalecia na época. Em 1996, ocorreu uma reforma na LDB, entrando em "cena" o chamado Ensino Fundamental e Ensino Médio, entendidos como etapas da educação básica, porém essa versão integrou à educação básica o ensino infantil.

Essa mesma publicação refere que a LDB Lei N 9.394/96, atualizada em março 2017 apresenta a composição da educação escolar dividida em dois grandes níveis, de um lado a educação básica da qual fazem parte a educação infantil, ensino fundamental e ensino médio e, de outro lado a educação superior (LDB Lei 9.394/96, art. 21). Já, nos artigos 22 e 23 respectivamente, a LDB cita que: 
A educação básica tem por finalidades desenvolver o educando, assegurar-lhe a formação comum indispensável para o exercício da cidadania e fornecer-lhe meios para progredir no trabalho e em estudos posteriores.

A educação básica poderá organizar-se em séries anuais, períodos semestrais, ciclos, alternância regular de períodos de estudos, grupos não seriados, com base na idade, na competência e em outros critérios, ou por forma diversa de organização, sempre que o interesse do processo de aprendizagem assim o recomendar. (LDB Lei $\mathrm{n}^{\circ}$ $9.394 / 96$, art. 22 e 23,2017 , p. 17 )

Diante destas tais finalidades de desenvolver o educando, que as metodologias ativas têm sido discutidas e até mesmo aplicadas no meio educacional, demandando aos professores/as e instituições reflexões acerca de suas práticas docentes, em prol da aprendizagem por parte do aluno/a.

\title{
2. Método
}

Este estudo qualitativo, utilizou-se de uma revisão bibliográfica em dissertações produzidas em âmbito nacional que contemplaram os temas metodologia ativa, sala de aula invertida, sendo que a busca dos dados foi realizada no período de 2014 a 2018 , na base de dados da CAPES de teses e dissertações. Para Gil (2007, p. 44) "a pesquisa bibliográfica é desenvolvida com base em material já elaborado, constituído principalmente de livros e artigos científicos".

Esse método foi utilizado, em virtude de que o campo foco da coleta dos dados foi a bibliografia acerca do tema investigado (Tozoni-Reis, 2009). Nesse âmbito, o trabalho buscou evidenciar quantitativamente o número de estudos publicados sobre a temática. Além de demonstrar qualitativamente os principais resultados e tendências encontradas nessas pesquisas.

\section{Procedimento}

Essa revisão bibliográfica foi empreendida através das seguintes etapas: escolha do tema, definição do problema de pesquisa, busca na base de dados da CAPES de teses e dissertações para composição da amostra, elaboração dos resultados e discussão. Para construção da revisão bibliográfica utilizou-se, de acordo com os operadores lógicos booleanos "and", "or" e "not" com os seguintes descritores: "metodologia ativa" and "sala de aula invertida".

\begin{abstract}
A busca booleana é a aplicação da Lógica de Boole a um tipo de sistema de recuperação da informação, no qual se combinam dois ou mais termos, relacionados por operadores lógicos, que tornam a busca mais restrita ou detalhada. As estratégias de busca são baseadas na combinação entre a informação contida em determinados documentos e a correspondente questão de busca, elaborada pelo usuário do sistema. (Saks, 2005, p. 4)
\end{abstract}

Nesse sentido, foram consultados o catálogo da base de dados da CAPES, das teses e dissertações correspondentes ao período de 2014 a 2018. Após a busca criteriosa das publicações, foi realizada a leitura dos títulos e resumos, bem como o estabelecimento de critérios de inclusão e exclusão. Posteriormente, as dissertações (não foram encontradas nenhuma tese) selecionadas foram lidas de forma criteriosa na integra, para possibilitar a descrição dos resultados. As dissertações localizadas estão divididas entre dissertações de mestrado scrito sensu e dissertações de mestrado profissional. 
Foram incluídas apenas as dissertações nacionais que utilizaram o descritor "sala de aula invertida" and "metodologia activa" encontrados com textos completos e disponíveis online, independentemente de serem dissertação de mestrado scrito sensu ou de mestrado profissional. Com relação ao idioma de busca, limitou-se ao português. Após a leitura detalhada do título e resumo dos trabalhos, foram selecionados os que estabeleciam um diálogo relacionado à especificidade do tema.

\section{Resultados}

Através da busca realizada nas bases de dados de teses e dissertações da CAPES resultaram 8 (oito) dissertações que foram inclusas nessa revisão de literatura, sendo 6 de mestrado scrito sensu e 2 de mestrado profissional. A quadro 1 mostra o número de dissertações encontradas para realização desse estudo. Na figura 2 encontra-se o percurso metodológico para seleção das dissertações. O quadro 2 apresenta uma síntese das dissertações incluídas nesse estudo, contendo título, ano de publicação, autores, tipo de estudo, objetivos, instrumentos utilizados/participantes das amostras e os resultados obtidos em cada um dos estudos de tais dissertações.

Em relação ao ano de publicação das dissertações encontradas, observa-se que os anos de 2015 (n=21) e 2016 (n=9) tiveram maior concentração de dissertações focadas na temática em questão, os anos anteriores e posteriores apresentam um número reduzido de dissertações voltadas à temática, conforme explicitado no quadro 1, a qual estão categorizadas por "D" de dissertação, seguida do número de ordem.

Quadro 1. Número de dissertações

\begin{tabular}{lcccccc}
\hline \multicolumn{1}{c}{ ANO } & TOTAL & \% & $\begin{array}{c}\text { MESTRADO } \\
\text { SCRITO SENSU }\end{array}$ & $\begin{array}{c}\text { MESTRADO } \\
\text { PROFISSIONAL }\end{array}$ & SELECIONADOS & \% \\
\hline 2018 & 01 & 2,8 & 01 & - & 1 & 12,5 \\
2017 & 03 & 8,3 & 01 & 02 & 4 & 50,0 \\
2016 & 09 & 25,0 & 04 & 05 & 3 & 37,5 \\
2015 & 21 & 58,3 & 11 & 10 & 0 & - \\
2014 & 02 & 5,6 & 01 & 01 & 0 & - \\
\hline Total & 36 & 100 & 18 & 18 & 8 & 100 \\
\hline
\end{tabular}

Fonte: Dados organizados pelos autores, com base na consulta à base de dados CAPES.

A busca empreendida no período de 2014 a 2018, resultou em um total de 36 dissertações, sendo 18 dissertações de mestrado scrito sensu e 18 dissertações de mestrado profissional, porém apenas 8 , sendo 6 de mestrado scrito sensu e 2 de mestrado profissional atenderam aos critérios de inclusão deste estudo.

Nas pesquisas empíricas selecionadas e sintetizadas no quadro 1, pode-se perceber que as práticas da metodologia ativa têm se tornado uma proposição real no contexto educacional. D1 apontou resultados satisfatórios e perfeitamente aplicáveis numa formação de professores de matemática, utilizando o modelo denominado sala de aula invertida. Nesse sentido, o resultado satisfatório (Díaz Barriga, 2010; Carranza Alcántar e Caldera Montes, 2018) deve-se ao fato de que "os professores ainda não possuem habilidades suficientes para gerar oportunidades de aprendizagem que ajudem os/as alunos/as". Já a autora da D2 apontou como resultado a adoção da prática da sala de aula 
invertida como algo positivo, já que também vivemos momentos de mudança na era digital, porém no estudo em questão o foco recaiu sobre o recurso vídeo.

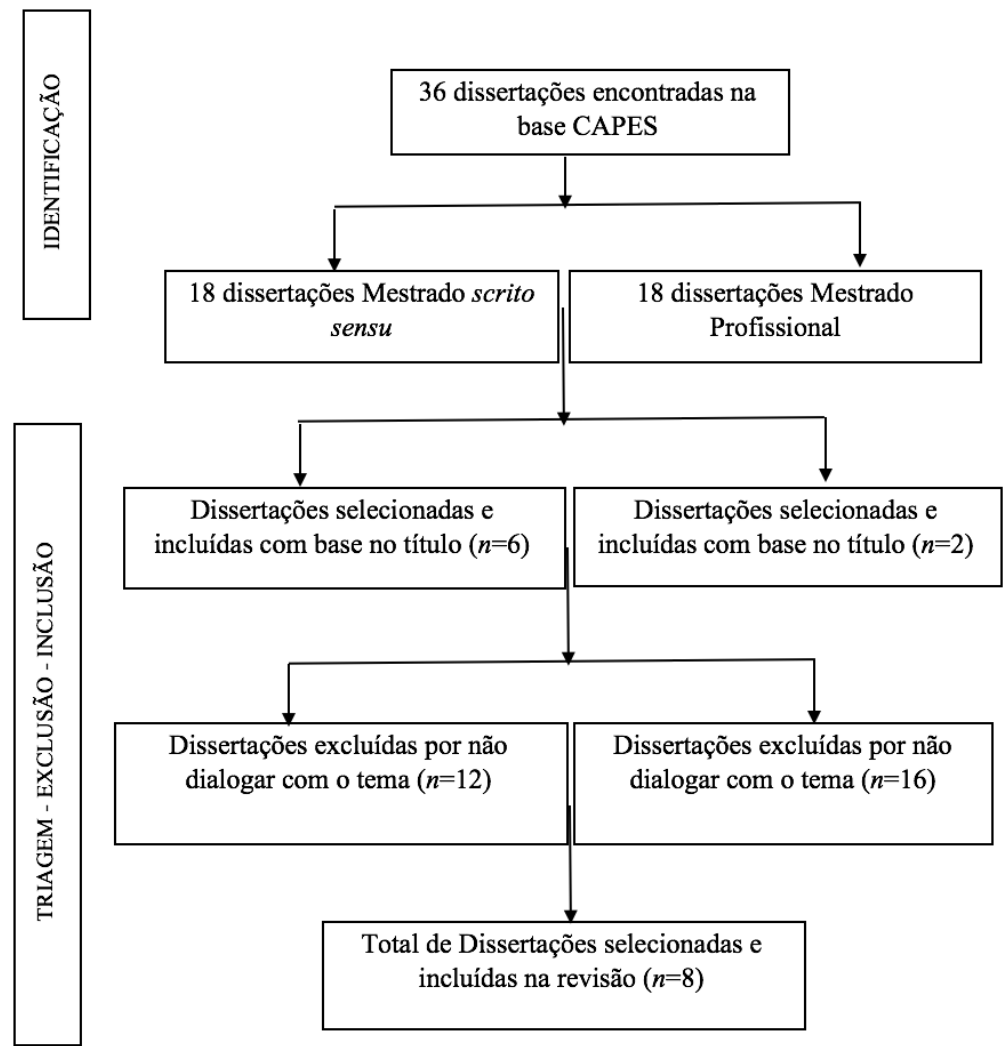

Figura 2. Percurso metodológico de seleção de dissertações Fonte: Elaborado pelos autores.

A utilização desse recurso corrobora com o entendimento de Bergmann e Sams (2018), pois o/a aluno/a se apropria do conteúdo de forma antecipada e, em sala de aula são promovidas as discussões. A autora da D3 explicitou que em seu estudo percebeu que a inovação da sala de aula invertida fora imposta pela direção do colégio, mas que os professores demonstraram interesse nos momentos formativos e que embora os resultados apontem para uma ressignificância nas práticas educativas, isso não representa a realidade da maioria das escolas de educação básica brasileira, até porque essa trata-se de uma escola com infraestrutura (física e digital) de ponta e o universo pesquisado foi de apenas oito professores.

O fato de os professores aderirem aos momentos formativos, corrobora com as ideias de Freire (1987), quando este revelou a importância de "o educador educar-se enquanto educa”. Quanto à D4, percebe-se que o autor se ateve ao ensino híbrido, sob dois enfoques: rotação por estações e sala de aula invertida, concluindo que o ensino híbrido possui potencial de aplicabilidade. 
Quadro 2. Síntese das dissertações incluídas no estudo

Título, Ano, Autor e Local

D1 Metodologias ativas: o papel da pesquisa na formação de professores de matemática 2018. PUC/RS. Daiane Renata Machado

\section{Palavras-Chave}

Metodologias ativas; Sala de aula invertida; Tecnologias na educação; Pesquisa em sala de aula; Formação de professores de matemática

Tipo de Estudo

Pesquisa de cunho qualitativo

Objetivo e Instrumentos de coleta

Analisar o papel da pesquisa na formação de professores de Matemática possibilitado pelas Metodologias Ativas, a partir da perspectiva dos professores. Pretende-se responder à questão: Como a pesquisa é abordada na formação de professores de Matemática por meio das

Metodologias Ativas em uma IES do RS. Especificamente, tratou-se de analisar a percepção de pesquisa dos professores do curso de Licenciatura em Matemática de uma IES do RS, participante desta investigação,compreender as percepções dos professores do curso, participantes da pesquisa, acerca das condições possibilitadas pelas Metodologias Ativas para o uso de diferentes recursos pedagógicos, métodos e estratégias de ensino; identificar, caso existam, as mudanças da relação professor/estudante na perspectiva dos professores desse curso; analisar o papel da pesquisa e como ela se operacionaliza durante a formação de professores de Matemática nessa IES. Diário de campo; entrevista semiestruturada e consulta a documentos oficiais. Foram pesquisados professores

\section{Resultados}

Os resultados da análise permitiram compreender como a Metodologia Ativa da Sala de Aula Invertida aborda a pesquisa na formação de professores, na perspectiva os docentes de Matemática do curso de Licenciatura em Matemática. E por fim, conclui-se que o objetivo do curso é formar professores de Matemática pesquisadores, autoconfiantes, em um modelo de ensino considerado inovador, devido à inversão da sala de aula possibilitado pelo uso das tecnologias que colaboram para a integração de espaço e tempo, entre as quais destacam-se: computadores; smartphones; tablets; ambientes virtuais, dentre outros

\section{Título, Ano, Autor e Local}

D2 O uso do vídeo na sala de aula invertida: uma experiência no Colégio Arbos de Santo André.

2017. PUC/SP. Veronica Andrea Peralta Melendez

\section{Palavras-Chave}

Sala de aula invertida; Ensino-aprendizagem; Estilos de aprendizagem; Papel do professor; Papel do aluno

Tipo de Estudo

Pesquisa qualitativa com caráter exploratório

\section{Objetivo e Instrumentos de coleta}

A utilização dos vídeos educacionais como ferramenta de aprendizagem na Sala de Aula Invertida e sobre quais aplicativos e estratégias podem ser usados com esse novo modelo pedagógico para que haja um bom aproveitamento, tanto por parte do aluno, quanto por parte do professor. A pesquisa observa o uso dos vídeos na Sala de Aula Invertia no Colégio Arbos, de Santo André/SP e tenta entender se e como o uso do vídeo na sala de aula invertida auxilia na construção do ensino aprendizagem. Observação aula professor Ruy no Colégio

\section{Resultados}

A prática do modelo pedagógico da Sala de Aula Invertida e o uso dos vídeos no Colégio, nas aulas do professor Ruy, concluiu-se que a escola pode adotar essa prática porque as suas necessidades de aprendizagem na era digital também mudaram no decorrer dos anos

\section{Título, Ano, Autor e Local}

D3 A sala de aula invertida no contexto da educação básica: possibilidades de mudança na prática docente 2017. PUC/PR. Caroline Ferreira Costa 


\section{Palavras-Chave}

Sala de aula invertida; Prática docente; Mudança educacional; Metodologias ativas; Educação básica

Tipo de Estudo

Estudo de caso, com 11 professores, 1 diretora educacional e 1 analista de tecnologia educacional

Objetivo e Instrumentos de coleta

Identificar as expressões de mudança nas práticas de professores da educação básica que aplicaram a metodologia em suas aulas, durante os anos de 2015 e 2016, em uma escola privada situada na região Centro-Norte brasileira. Foram realizadas entrevistas semiestruturadas com todos os participantes e analisados os planos de aula dos professores. A análise de dados foi realizada utilizando a técnica de análise em espiral aplicada dentro do software Atlas.ti

\section{Resultados}

As mudanças reconhecidas nas práticas docentes, os aspectos relacionados às dificuldades enfrentadas pelos professores e as percepções pessoais sobre as mudanças geradas em suas próprias práticas resultantes deste estudo configuram um cenário favorável para reflexões acerca do uso de metodologias ativas, especificamente, no campo da educação básica, bem como dos desafios e benefícios na implementação de uma nova abordagem pedagógica. Embora, ressalta a autora que, a sala de aula invertida foi inserida de forma impositiva pela direção da escola e que o contexto não representa a maioria das escolas de educação básica no Brasil

Título, Ano, Autor e Local

D4 A aplicação do ensino híbrido na educação profissional e tecnológica: potencialidades e dificuldades

2017. UFSM/RS. Alberto Pedro Antonello Neto

\section{Palavras-Chave}

Ensino híbrido Rotação por estações; Sala aula invertida. Metodologias ativas; inovação na educação

\section{Tipo de Estudo}

Estudo de caso, que surgiu da necessidade de direcionar o ensino às necessidades dos alunos contemporâneos, que estão imersos na tecnologia e anseiam por práticas de ensino diferenciadas.

Objetivo e Instrumentos de coleta

Estudar as potencialidades e dificuldades da utilização do uso desta metodologia ativa na EPT. Propôs-se a aplicação da metodologia ativa denominada Ensino Híbrido (EH), nos modelos de Rotação por Estações e Sala de Aula Invertida, numa disciplina do Curso Técnico em Meio Ambiente, do Colégio Politécnico da Universidade Federal de Santa Maria. Os objetivos específicos foram: estudar formas de aplicar o ensino híbrido na EPT; selecionar ferramentas dentro do AVA Moodle que auxiliem para o processo de ensino; aplicar estratégias de ensino com o ensino híbrido em uma disciplina da EPT; identificar as potencialidades e as dificuldades encontradas

\section{Resultados}

Pelos resultados obtidos o Ensino Hibrido tem grande potencial para aplicação na EPT, contudo os recursos de infraestrutura necessitam de um redimensionamento para atender a demanda de forma eficiente

Título, Ano, Autor e Local

D5 Transposição e ressignificação das metodologias ativas para o ensino médio, à luz das Políticas educacionais brasileiras

2017. VITÓRIA/ES. Marcos Augusto Martins Cardoso

Palavras-Chave

Aprendizagem; Ensino Médio; Metodologias Ativas

Tipo de Estudo

Pesquisa bibliográfica e exploratória 


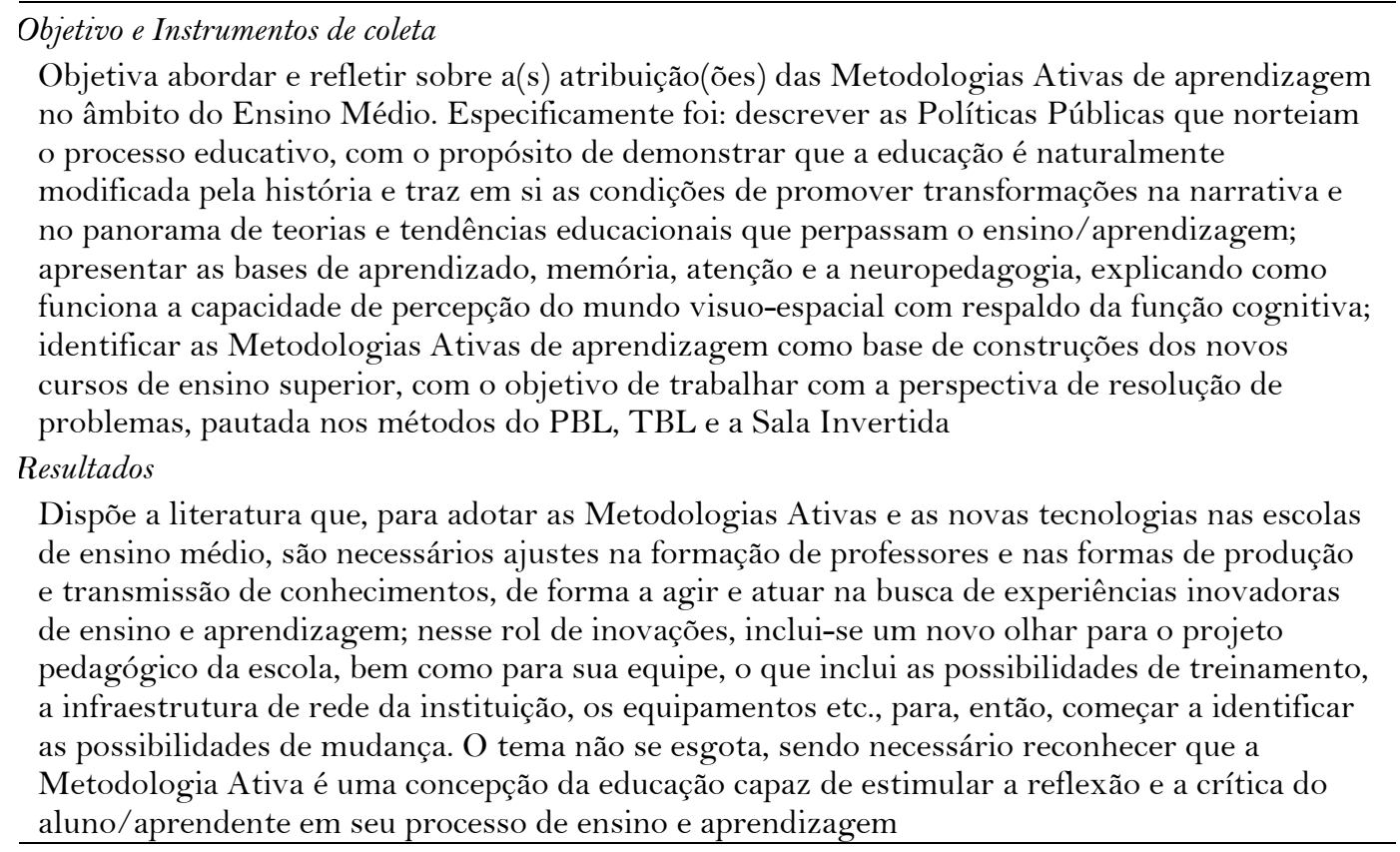

Título, Ano, Autor e Local

D6 Metodologias ativas de aprendizagem interferem no desempenho de estudantes 2016. USP/SP. Iara Yamamoto

Palavras-Chave

Metodologias ativas de aprendizagem e ensino; Ensino híbrido MOOC-Massive Open Online Course. Ensino e aprendizagem; Alinhamento construtivo

Tipo de Estudo

Não ficou claro

Objetivo e Instrumentos de coleta

Analisa fatores que sustentam o uso das metodologias ativas para o aumento do desempenho dos estudantes para a aprendizagem significativa. Para avaliar a interferência da metodologia ativa de aprendizagem no desempenho, participaram da análise estudantes universitários, de duas instituições particulares, na área de Ciências Sociais Aplicadas, que após um semestre responderam a dois questionários de escalas validadas estatisticamente: Academic Motivation Scale e Escala Estratégica de Aprendizagem para ambientes online. Técnicas de análise multivariada, com análise de componentes principais e análise de agrupamento. Para a caracterização dos grupos de motivação obtidos foram calculadas as frequências dos grupos formados e médias dos componentes principais, bem como as marcações de significância estatística para o teste-t de diferença de médias e técnicas de modelo de regressão para avaliar as médias finais (notas) dos estudantes

Resultados

Os principais resultados demonstram o êxito da introdução das metodologias ativas está diretamente relacionado a importância do envolvimento de todos os atores desse processo, com destaque as instituições de ensino e professores, para a formação de um indivíduo capaz de transformar a sua vida, o seu meio e a nossa sociedade

Título, Ano, Autor e Local

D7 Desafios e possibilidades da implantação da metodologia sala de aula invertida: Estudo de caso em uma IES privada

2016. Faculdade Pedro Leopoldo/MG. Paulo Rodrigues Milhorato

Palavras-Chave

Sala de aula invertida; Sociedade do conhecimento; Tecnologia

Tipo de Estudo

Pesquisa descritiva com abordagens qualitativa e quantitativa

Objetivo e Instrumentos de coleta 
Teve como objetivo descrever os impactos da metodologia sala de aula invertida em um IES Privada. Com base neste contexto, a pergunta norteadora desta pesquisa é: Quais são as vantagens e dificuldades na aprendizagem dos sujeitos envolvidos no processo sala de aula invertida? Portanto, o objetivo geral delineado foi identificar as vantagens e as dificuldades na aprendizagem dos sujeitos envolvidos no processo sala de aula invertida e como objetivos específicos descrever e caracterizar a metodologia sala de aula invertida; o perfil dos sujeitos (aluno) envolvidos na pesquisa; identificar o grau de envolvimento dos sujeitos (aluno/professor) no processo de sala de aula invertida. Os dados para atender à abordagem quantitativa foram colhidos por meio de questionário disponibilizado na ferramenta Google Docs e/ou impressos, aplicado aos alunos da Faculdade Pitágoras, unidade Venda Nova. Para abordagem qualitativa, utilizou-se o método de entrevista com professores envolvidos e observação participante pelo autor da pesquisa

Resultados

Os resultados revelam que o perfil do jovem é favorável à aplicação da modelo sala de aula invertida: são alunos jovens e com alto contato com a tecnologia. Entretanto sua rotina diária, uma formação de base deficiente e a necessidade de trabalhar para custear uma IES privada tornam complexa a aplicação deste modelo, tendo em vista que a modelo sala de aula invertida requer conhecimento e interação com a tecnologia, porém também tempo para realização das atividades e estudo do conteúdo online antes dos encontros presenciais

Título, Ano, Autor e Local

D8 Sala de aula invertida: uma abordagem para combinar metodologias ativas e engajar alunos no processo de ensino-aprendizagem

2016. UFSM/RS. Elieser Xisto da Silva Schmitz

\section{Palavras-Chave}

Sala de aula invertida; Ensino híbrido; Metodologias ativas de aprendizagem

Tipo de Estudo

O estudo descritivo e exploratório, com caráter qualitativo

Objetivo e Instrumentos de coleta

A proposta da pesquisa centrou-se na apresentação dos elementos que caracterizam e que definem a sala de aula invertida para, posteriormente, questionar o grau de familiaridade, de aplicações e de interesse dos docentes da UFSM por esse modelo

\section{Resultados}

Os resultados da pesquisa mostraram que o modelo era desconhecido pela maioria dos participantes, mas muitos identificaram aspectos de inversão em suas práticas docentes, ainda que de forma parcial. Quanto às demandas por formação, as metodologias de maior interesse dos professores para inversão de suas salas de aula foram o Peer Instruction e o Just-in-Time Teaching. Já as tecnologias que os docentes indicaram querer aprender a usar foram: lousa digital interativa, softwares de edição de vídeo/áudio e screencast. Por fim, ases temáticos que mais despertaram interesse por formação dos professores foram as metodologias ativas de aprendizagem e o ensino híbrido

Fonte: Elaborado pelos autores com base à consulta banco de dados CAPES

$\mathrm{Na}$ D5, em suas conclusões, o autor afirma que de acordo com literaturas pesquisadas para adoção das metodologias ativas nas escolas de ensino médio é primordial ajustar a formação dos professores, assim como as formas de produção e transmissão de conhecimentos e que nisso inclui-se um “novo olhar para o projeto pedagógico da escola”, coloca ainda que o tema é inesgotável, tal ideia filia-se ao exposto por Horn e Staker (2015) quando disseram que somos todos híbridos, pois na educação todos aprendem, ensinam, consomem e produzem conhecimento, bem como informações cotidianamente. Na D6, a autora concluiu que embora não se possa generalizar os resultados em virtude de cada instituição possuir suas peculiaridades, os resultados apontaram êxito na adoção de metodologias ativas, em especial quando a instituição e os professores se envolvem, 
também Horn e Staker (2015) compartilham da mesma ideia quando referem as interações sociais aliadas a momentos de reelaboração, por exemplo. $\mathrm{O}$ autor da $\mathrm{D} 7$ concluiu que a pesquisa acerca da metodologia ativa apresentou prós e contras, sendo que o aspecto positivo foi a aceitação por parte dos alunos, em especial os jovens, mas no contraponto negativo, foram registrados alguns apontamentos de dificuldade de acesso aos conteúdos/atividades online, em virtude de falta de tempo (pois trabalham) impactando no conteúdo a ser abordado em sala de aula, forçando o professor a retomar na íntegra, o que o remete aos moldes de ensino tradicional. Todavia, Moran (2013) defendeu a ideia de que as instituições podem escolher um caminho de mudanças gradativas, mantendo o modelo de ensino tradicional, tendo como prioridade o envolvimento do aluno em tais metodologias. Já o autor da D8 assinalou que os estudos demonstraram que existe possibilidade de promoção da sala de aula invertida através da disponibilização de material didático e instrucional, assim como necessidade de capacitação ao corpo docente para o uso de metodologias ativas de ensino.

\section{Discussão e conclusões}

No presente estudo, objetivou-se investigar como ocorrem as práticas da metodologia ativa, especificamente sala de aula invertida no ensino básico. Nesse sentido foram analisadas oito dissertações de mestrado scrito sensu e mestrado profissional, no período corresponde de 2014 a 2018. Para Moran (2017),

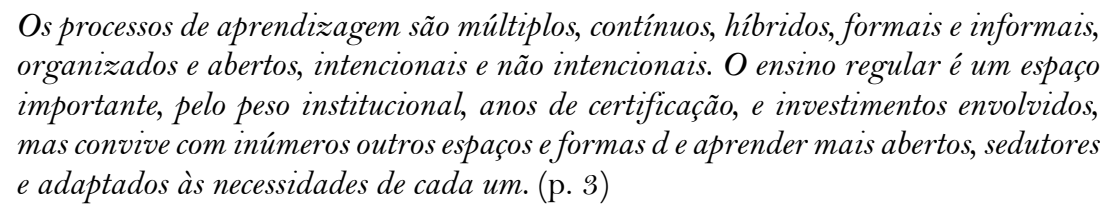

Os processos de aprendizagem são múltiplos, contínuos, híbridos, formais e informais, organizados e abertos, intencionais e não intencionais. O ensino regular é um espaço importante, pelo peso institucional, anos de certificação, e investimentos envolvidos, mas convive com inúmeros outros espaços e formas de aprender mais abertos, sedutores e adaptados às necessidades de cada um. (p. 3)

Diante disso, percebe-se a metodologia ativa, independente do modelo, mas em especial a sala de aula invertida emerge no meio educacional, abrangendo desde a educação básica até o nível superior. Porém, o que se observa de acordo com as dissertações que compuseram este estudo, é que não há um consenso de que a sala de aula invertida necessariamente requer um aparato tecnológico, embora em algumas pesquisas esse argumento apareça de forma contundente, enquanto que em outras defendeu-se a ideia de que inverter sala de aula, é possível mesmo em situações em que tal recurso seja escasso. Por outro lado, se pensarmos em sala de aula invertida como prática há que se considerar o fundamental papel da tecnologia, assim como a mudança de papel do docente que passa a ser de mediador do processo. Revendo os pressupostos teóricos de Anastasiou e Alves (2007) sobre estratégias de ensino-aprendizagem, podemos concluir que sala de aula invertida se enquadra na condição de estratégia de ensino-aprendizagem, tendo em vista que as sugestões de dinamizar as aulas através das mais diversas estratégias já foram sinalizadas em outros tempos. Os autores Camargo e Daros (2018) remetem à ideia da combinação e adaptação das estratégias e que ao planejar a aula, o/a professor/a possa determinar o limite de seu uso.

Ainda sobre a perspectiva de dinamizar as aulas, Tardif (2014) discorre sobre os saberes, categorizando-os em saberes docentes, da formação profissional, disciplinares, curriculares e os saberes experienciais, no que a autora afirma que quando tais saberes são instigados em sala de aula, nas interações inovadoras com os/as alunos/as há uma 
convergência com os aspectos intencionais educativos. Já Camargo e Daros (2018) entende que inovar em sala de aula deve ser encarado como um processo e não como um fim, pois mudanças desse tipo necessitam partir de "questionamentos das finalidades da própria experiência educacional como impulsora da reflexão-ação docente”.

\begin{abstract}
De todo modo, na educação básica e no nível superior são demandados novos formatos de interação discente-docente-discente e ao que tudo indica as metodologias ativas estão conquistando espaço, mas ainda requerem apropriação por parte dos atores do meio acadêmico. Nesse sentido, é fundamental que seja explicitada a concepção de educação que se tem como elemento norteador, ou seja, precisa-se ter clareza de qual é a função social da escola e da universidade, de para que se ensina e de que quais resultados se espera por meio do ensino que se propõe. (Camargo e Daros, 2018, p. 5)
\end{abstract}

A autora ainda refere que existem inúmeras pesquisas indicando que a aprendizagem na educação básica e superior necessita adotar formatos mais significativos de interação. Inovar nas salas de aulas tem sido uma demanda prática e, embora tenhamos focado na modelo sala de aula invertida, podemos concluir que se espera que os/as docentes compreendam que não existe um único modelo aplicável atendendo as mais diversas necessidades de ensino-aprendizagem (Mora Reyes e Morales Rivera, 2016).

Por fim, há que se ressaltar que esta pesquisa apresenta como limitador o fato de ter sido realizada em nível nacional (base de dados do Brasil), o que nos permite conjecturar que esses estudos devem ser ampliados para um universo maior, considerando produções internacionais acerca da temática sala de aula invertida- enquanto metodologia ativa- bem como aprofundar investigações em outros modelos existentes, por tratar-se de um tema pouco explorado.

\title{
Referências
}

Anastasiou, L. G. C. e Alves, L. P. (2007). Processos de ensinagem na universidade: Pressupostos para as estratégias de trabalho em aula/org. Santa Catarina: Univille Universidade.

Bergmann, J. e Sams, A. (2018). Sala de aula invertida: Uma metodologia ativa de aprendizagem. Rio de Janeiro: LTC.

Camargo, F. e Daros, T. (2018). A sala de aula inovadora: Estratégias pedagógicas para fomentar o aprendizado ativo. Porto Alegre: Penso.

Carranza Alcántar, M. R. e Caldera Montes, J. F. (2018). Percepción de los estudiantes sobre el aprendizaje significativo y estrategias de enseñanza en el Blended Learning. REICE. Revista Iberoamericana sobre Calidad, Eficacia y Cambio en Educación, 16(1), 73-88. https://doi.org/10.15366/reice2018.16.1.005

Díaz Barriga, F. B. (2010). Estrategias docentes para un aprendizaje significativo. Ciudad de México: Mc Graw Hill.

Flipped Learning Network. (2014). The four pillars of F-L-I-P. Recuperado de http://www.flippedlearning.org/domain/46

Freire, P. (1987). Pedagogía do oprimido. Rio de Janeiro: Paz e Terra.

Gil, A. C. (2007). Como elaborar projetos de pesquisa. São Paulo: Atlas.

Hattie, J. (2017). Aprendizagem visível para professores: Como maximizar o impacto da aprendizagem. Porto Alegre: Penso. 
Horn, M. B e Staker, H. (2015). Blended: Usando a inovação disruptiva para aprimorar a educação. Porto Alegre: Penso.

LDB-Lei de diretrizes e bases da educação nacional. Lei no 9.394/1996. Brasília: Senado Federal. Recuperado de http://www2.senado.leg.br/bdsf/item/id/529732

Martins da Silva, F. C., Sampaio Lima, A. e Bandeira Andriola, W. (2016). Avaliação do suporte de TDIC na formação do pedagogo: Um estudo em Universidade Brasileira. REICE. Revista Iberoamericana sobre Calidad, Eficacia y Cambio en Educación, 14(3), 77-93. https://doi.org/10.15366/reice2016.14.3.004

Mora Reyes, J. Z. e Morales Rivera, S. P. (2016). Fortalecimiento en los procesos lecto-escritos en primera infancia a través de blended-learning. REICE. Revista Iberoamericana sobre Calidad, $\begin{array}{llll}\text { Eficacia Cambio en } y \quad \text { Educación, } & 14(1),\end{array}$ https://doi.org/10.15366/reice2016.14.1.007

Moran, J. (2013). Educação híbrida: Um conceito-chave para a educação. En T. N. Bacich (Org.), Ensino híbrido: Personalização e tecnologia na educação (pp. 28-45). Porto Alegre: Penso.

Moran, J. e Bacich, L. (2018). Metodologias ativas para uma educação inovadora: Uma abordagem teórico-prática. Porto Alegre: Penso.

Saks, F. C. (2005). Busca booleana: Teoria e prática. Curitiba: Universidade Federal do Paraná.

Tardif, M. (2014). Saberes docentes e formação profissional. Petrópolis: Vozes.

Tozoni-Reis, M. F. C. (2009). Metodologia da pesquisa. Curitiba: IESDE Brasil S.A.

\section{Breve CV das autoras}

\section{Zeni Terezinha Gonçalves Pereira}

Mestranda PPG Educação, UNILASALlE. Pós-graduada em Gestão de Pessoas e Negócios (2017); em Formação Pedagógica de Professores (2012). Graduação em Administração de Empresas (1996). Professora Graduação Administração EAD ULBRA; Professora curso Técnico em Logística (EAd e Presencial) na QI Faculdade. Professora convidada da Disciplina Didática e Metodologia de Ensino, em Curso de PósGraduação Lato Sensu (Especialização) em Gestão de Trânsito e Mobilidade, na Faculdade Dom Bosco POA/Brasil (2015/2016/2017) e Pós-Graduação Lato Sensu em Psicologia do Trânsito (2014). ORCID ID: https://orcid.org/0000-0003-2773-5405. Email: ztgpereira@gmail.com

\section{Denise Quaresma da Silva}

Psicóloga, Pesquisadora do CNPQ - Bolsista de Produtividade - Nível 2 - CAED Educação. Programa de Pós-Graduação em Educação UNILASALLE, Programa de PósGraduação em Diversidade Cultural e Inclusão Social/FEEVALE. Pós-Doutora em Estudos de Gênero pela UCES (2011), Doutora (2007) e Mestre (2003) pela Universidade Federal do Rio Grande do Sul. Atua nas áreas dos Estudos de Gênero, Psicanálise, Psicologia e Educação, nos temas Educação sexual, Saúde sexual e reprodutiva, Gravidez na adolescência, Formação de professores, Políticas Públicas e Direitos Humanos. ORCID ID: https://orcid.org/0000-0002-3697-8284. Email: denisequaresmadasilva@gmail.com 